\title{
Staphylococcus aureus and Methicillin Resistant S. aureus in Commercial Soft Drink with Antimicrobial Resistance Test on Isolates in Ethiopia
}

\author{
Adem Hiko* \\ College of Veterinary Medicine, Haramaya University, Ethiopia
}

\begin{abstract}
Staphylococcus aureus is common food contaminant and responsible for food poising. The aim of this study was to assess prevalence of $S$. aureus and Methicillin Resistant S. aureus (MRSA) in commercial soft drinks (CSDs) with antimicrobial resistance test on the isolates in two towns of Ethiopia. A total of 774 samples of ready-to-drink CSDs were randomly purchases from different public supply locations and analyzed for $S$. aureus. MRSA were screened phenotypically using Cefoxitin (FOX $30 \mu \mathrm{g}$ ) disk diffusion method. All of studied CSD products were within manufacturer shelf life. An overall $28(3.6 \%)$ and $5(0.6 \%)$ S. aureus and MRSA were observed, respectively. Similar prevalence of $S$. aureus ranging from $1.0-4.8 \%$ and $1.2-6.6 \%$ were observed by product category and by public supply location, respectively. Significantly higher (10.7\%; OR=12, 95\%OR Cl: 6.1-23.7) S. aureus in carton box packed than in glass bottle canned $(2.3 \%)$ and metal canned $(2.4 \%)$ products were observed. S. aureus prevalence was higher in CSD products from Bangladesh (17.9\%; OR=21.6, 95\% OR Cl: 10.3-45.6) and Portugal (8.9\%; $\mathrm{OR}=9.8,95 \%$ OR Cl: 3.6-26.2) than from Ethiopia (1.3\%; OR=1.3, 95\% OR Cl: 0.5-3.3). Prevalence of MRSA ranged from $0-6.7 \%$ within studied variable. High $(64.3 \%) \mathrm{S}$. aureus were resistant to erythromycin followed by $32.2 \%$ to ampicillin. Equal, (21.4\%) of $S$. aureus were resistant to streptomycin, amoxicillin and chloramphenicol. All of MRSA were resistant erythromycin. Equal, $4(80.0 \%)$ MRSA were resistant to amoxicillin and chloramphenicol. No resistant $S$. aureus and MRSA were observed to gentamycin and trimethoprim-sulfamethoxazole. All MRSA isolates were also not resistant to ciprofloxacin. Eighteen $S$. aureus isolates were resistant to at least single to multiple of six drugs used in the study. Data indicated possible contamination of CDS products with S. aureus and MRSA including MDR strain during processing and post-process handling.
\end{abstract}

Keywords: Commercial soft drinks; S. aureus; Methicillin resistant; Antimicrobials resistance; Ethiopia

\section{Introduction}

Processed commercial soft drinks are industry products canned and bottled beverage. They are either energy drink, juice or water ready-todrink products getting popularity in food sectors [1]. They are produced and transported to a distance location to supply consumer under different handling conditions [2,3]. Risk of warmer weather condition and inadequate refrigeration were the principal causes of higher levels of contamination, increased diversity and change in microbial flora in the commercial product [2]. Range of spoilage microbial was reported from home-made tiger-nut beverages in Spain [3]. Abundant yeasts and fungi were isolated from yoghurts in Brazil [2]. The possible presences of some public health hazard microbial having most likely health threat in such processed products, including in the acidic products like juice, were also suggested, due to good acid-tolerance of such microbial [1-5]. Whether the products are produced by commercial or traditional methods, nonalcoholic beverages have risk of contamination with spoilage and public health pathogenic microbial [1-8].

Risk of contamination of bottled water and juices has also been reported. Presence microbial in and with contamination risk associated to traditional beverage in Ethiopia as also been reported by Ashanafi [4]. Staphylococcus aureus (S. aureus) are common contaminant food and responsible for food poising [9-13]. Again, there are also increasing public health impact of methicillin resistant S. aureus (MRSA) associated with food [14,15]. According to Karami et al. [16] phenotypic disk diffusion assays using cefoxitin had high sensitivity and specificity for detection of MRSA. However, investigation on occurrence of S. aureus and MRSA in commercial soft drink in Ethiopia was not yet assessed. The objective of this study was to assess the prevalence of $S$. aureus and MRSA in industrially produced commercial soft drink found on the markets of Ethiopia with antimicrobial resistance test on the isolates.

\section{Materials and Methods}

\section{Study design}

A cross-sectional study was employed to assess the occurrences of $S$. aureus and MRSA in commercial soft drinks available on the Chiro and Dire Dawa towns markets with drug resistance test on the isolates in Ethiopia.

\section{Study area location}

Study was conducted in Chiro $9^{\circ} 05^{\prime}-9^{\circ} 08^{\prime} \mathrm{N}, 40^{\circ} 52^{\prime} \mathrm{E}-40^{\circ} 87^{\prime} \mathrm{E}$ ) and Dire Dawa $\left(9^{\circ} 27^{\prime}-9^{\circ} 49^{\prime} \mathrm{N}, 41^{\circ} 38^{\prime}-42^{\circ} 19^{\prime} \mathrm{E}\right)$ towns located at about $350 \mathrm{~km}$ and $556 \mathrm{~km}$ distance from Addis Ababa, the Capital City, respectively in the eastern part of Ethiopia. The average annual temperature of Chiro with 33,670 population and Dira Dawa with 341,834 population was $20.2^{\circ} \mathrm{C}$ and $24.6^{\circ} \mathrm{C}$, respectively $[17,18]$.

\section{Sample size calculation}

Sample size was calculated using 50\% expected prevalence of Staphylococcus aureus in commercial soft drinks within 95\% Confidence Intervals $(\mathrm{CI})$ at $5 \%$ desired precision, according to the Thrusfield formula [19].

*Corresponding author: Adem $\mathrm{H}$, College of Veterinary Medicine, Haramaya University, Ethiopia, Tel: 251255530334; 251255530060; Fax: 251255530325/31; E-mail: adex.2010ph@gmail.com

Received March 11, 2018; Accepted April 17, 2018; Published April 24, 2018

Citation: Hiko A (2018) Staphylococcus aureus and Methicillin Resistant S. aureus in Commercial Soft Drink with Antimicrobial Resistance Test on Isolates in Ethiopia. J Microb Biochem Technol 10: 40-45. doi: 10.4172/1948-5948.1000393

Copyright: () 2018 Hiko A. This is an open-access article distributed under the terms of the Creative Commons Attribution License, which permits unrestricted use, distribution, and reproduction in any medium, provided the original author and source are credited. 


$$
\mathrm{n}=\frac{1.96^{2} * \mathrm{P}_{\text {exp }}\left(1-\mathrm{P}_{\text {exp }}\right)}{\mathrm{d}^{2}}
$$

Where, $n$ : Required sample size; $d=$ desired absolute precision; $\mathrm{P}_{\text {exp }}$ : Expected prevalence (50\%)

The minimum of 384 samples for each town which becomes 768 for both, but 774 samples were collected and examined.

\section{Sampling and sample handling}

Simple random sampling techniques were applied at public supply location in selected study towns. Whole volume of the sampled product, as it was canned, were randomly purchased. Information regarding expire date, product type, producing countries, source town, public supply locations and types of packaging material were immediately registered for each sample using specific identification number. Samples were immediately transported to Veterinary Microbiology Laboratory, College of Veterinary Medicine, Haramaya University on the day of sampling using ice box at $+4^{\circ} \mathrm{C}$ for laboratory examination.

\section{Description of studied products and considered risk factors}

The studied products were commercial soft drinks those packed into a volume of $125 \mathrm{ml}$ to $1000 \mathrm{ml}$ and available on the market. They were randomly purchased at points of public supply locations. As shown in Table 1, the available sampled products were described considering factors used for the study using expire date, product type, packaging material, source town, public supply locations and the producing county.

\begin{tabular}{|c|c|c|c|}
\hline \multicolumn{2}{|l|}{ Studied risk factors } & \multirow{2}{*}{$\begin{array}{c}\text { Total No. of } \\
\text { samples } \\
774\end{array}$} & \multirow{2}{*}{$\begin{array}{c}\text { Frequency } \\
100\end{array}$} \\
\hline Fynire date & Within shelf life & & \\
\hline Exple date & Expired & 0 & 0 \\
\hline \multirow{3}{*}{ Product category* } & Energy drink $(\mathrm{pH}=2.50-3.70)$ & 195 & 25.2 \\
\hline & Juice drink ( $\mathrm{pH}=3.3-4.19)$. & 373 & 48.2 \\
\hline & Bottled water $(\mathrm{pH}=7.0-7.2)$ & 206 & 26.6 \\
\hline \multirow{4}{*}{ Packaging material } & Carton box & 84 & 10.9 \\
\hline & Glass bottle & 259 & 33.5 \\
\hline & Metal can & 246 & 31.8 \\
\hline & Plastic bottle & 185 & 23.9 \\
\hline \multirow{5}{*}{$\begin{array}{l}\text { Public supply } \\
\text { locations }\end{array}$} & Hotel & 130 & 16.8 \\
\hline & Open Market & 152 & 19.6 \\
\hline & Restaurants & 166 & 21.4 \\
\hline & Street & 156 & 20.2 \\
\hline & Supermarkets & 170 & 22.0 \\
\hline \multirow{2}{*}{ Source town } & Dire Dawa town & 385 & 49.7 \\
\hline & Chiro town & 389 & 50.3 \\
\hline \multirow{8}{*}{ Country of origin } & Bangladesh & 45 & 5.8 \\
\hline & Egypt & 60 & 7.8 \\
\hline & Ethiopia & 317 & 41.0 \\
\hline & Portugal & 45 & 5.8 \\
\hline & Saud Arabia & 49 & 6.3 \\
\hline & Thailand & 120 & 15.5 \\
\hline & UAE Dubai & 69 & 8.9 \\
\hline & Yemen & 69 & 8.9 \\
\hline \multicolumn{2}{|l|}{ Total } & 774 & 100 \\
\hline
\end{tabular}

*Note: The $\mathrm{pH}$ is indicated in that different types of products having different $\mathrm{pH}$ were examined

Table 1: Description and proportional distribution the sampled commercial soft drink available on the studied towns by studied risk factors.

\section{Staphylococcus aureus isolation and characterization}

Using 1:10 $\mathrm{ml}$ enrichment procedure [5,20], each sample was enriched at proportion of $1 \mathrm{ml}$ sample to $9 \mathrm{ml}$ of Buffered Peptone Water (BPW) and incubated for $24 \mathrm{~h}$ at $37^{\circ} \mathrm{C}$. A loop full of enrichment was streaked on $7 \%$ heparinized sheep blood based agar plate (Oxoid) and incubated at $37^{\circ} \mathrm{C}$ for $24 \mathrm{~h}$ under aerobic condition. Presumptive Staphylococcus colony was determined based on its opaqueness, whitish or creamy, grayish or yellowish colonies and beta hemolysis morphological characteristic [21]. Suspected colonies were further gram stained. Those with gram positive grape like colonies were transferred on mannitol salt agar and incubated at $37^{\circ} \mathrm{C}$ for $24 \mathrm{~h}$. The characteristic colony were transferred on to nutrient agar and incubated at $37^{\circ} \mathrm{C}$ for $24 \mathrm{~h}$. Biochemical test including catalase test, oxidase test, coagulase test by using rabbit plasma and DNase test to detection of DNase activity (for detection of deoxyriboneuclease enzyme) were conducted to confirm S. aureus [22].

\section{Methicillin resistant Staphylococcus aureus (MRSA) identification}

All isolates of $S$. aureus were tested using Kirby-Bauer disk diffusion method for Cefoxitin (FOX/30 $\mu \mathrm{g}$ ) [23-25]. According to Karami et al. [16], phenotypic cefoxitin disk diffusion assays methods had high sensitivity and specificity for detection of MRSA. On the other hand, Methicillin was bane from market. Thus, MRSA was identified phenotypically by using cefoxitin disk diffusion method [24,25]. Overnight freshly grown $S$. aureus cultures were inoculated into $5 \mathrm{ml}$ Brain Heart Infusion Broth (Merck, Germany). The inoculated broth was incubated for $4 \mathrm{~h}$ to approximately $10^{6} \mathrm{CFU} / \mathrm{ml}$ at McFarland $0.5 \%$ level of turbidity. The bacterial lawn was evenly spread on Mueller Hinton agar (Oxoid, UK) using sterile cotton swabs. The culture was incubated $37^{\circ} \mathrm{C}$ for $24 \mathrm{~h}$. Zone of bacterial growth inhibition was measured using caliper. The isolates were then classified susceptible, intermediate or resistant. Isolates with inhibition zone diameter of $\leq$ $21 \mathrm{~mm}$ was registered as methicillin resistant and determined as MRSA while those with $\geq 22 \mathrm{~mm}$ diameter of inhibition were reported as methicillin sensitive (none-MRSA) [24].

\section{Antimicrobial susceptibility test}

Antimicrobial susceptibility test was done on all of 72 isolates by the Kirby-Bauer disk diffusion method [23,24]. The tested bacterium was taken from an overnight freshly grown culture and inoculated into $5 \mathrm{ml}$ Brain Heart Infusion Broth (Merck, Germany). The inoculated broth was incubated for $4 \mathrm{~h}$ at $37^{\circ} \mathrm{C}$ to approximately $10^{6} \mathrm{CFU} / \mathrm{ml}$ at McFarland $0.5 \%$ level of turbidity. With this culture, a bacterial lawn was spread on Mueller Hinton agar (Oxoid, UK). Antimicrobials against disk (Oxoid, UK) including amoxicillin (AML $30 \mu \mathrm{g}$ ), ampicillin (AMP $10 \mu \mathrm{g}$ ), chloramphenicol (C $30 \mu \mathrm{g})$, gentamycin (CN $30 \mu \mathrm{g}$ ), ciprofloxacin (CIP $10 \mu \mathrm{g}$ ), cefoxitine (FOX $30 \mu \mathrm{g}$ ), erythromycin (ET 15 $\mu \mathrm{g})$ streptomycin (S $10 \mu \mathrm{g})$ and trimethoprim-sulfamethoxazole (SXT $1.25 / 23.75 / \mu \mathrm{g}$ ) were mounted. The culture was incubated $37^{\circ} \mathrm{C}$ for $24 \mathrm{~h}$. Result was interpreted using the diameter of zone of bacterial growth inhibition surrounding the disc $[23,24]$.

\section{Data analysis}

Data was entered into Microsoft Excel 2013@ and calculated using Stata Ver. 11, SPSS 20 (IBM Corp., Armonk, NY) and WinPepi 11.35 (Abramson JH). The results were described in frequency distributions and percentages for which the $95 \%$ Confidence Interval (CI) Midd-prevalence exact were calculated. Odds ratio (OR) and $95 \%$ OR CI were also calculated determine the significance differences within studies factors. 
Citation: Hiko A (2018) Staphylococcus aureus and Methicillin Resistant S. aureus in Commercial Soft Drink with Antimicrobial Resistance Test on Isolates in Ethiopia. J Microb Biochem Technol 10: 40-45. doi: 10.4172/1948-5948.1000393

\section{Results}

As shown in Table 1, all of studied products are within manufacturer shelf life. The majorities (48.2\%) are juice drink. Of the studied sample, relatively low (10.9\%) were those packed in carton box? Most of them are of products of Ethiopia ( $40.0 \%$ followed by the Thailand (15.5\%). However, the samples were evenly distributed at all public supply location and both study towns.

\section{Staphylococcus aureus and MRSA prevalence}

An overall 28 (3.6\%) of sample was positive for S. aureus. Total prevalence of MRSA was 5 (0.6\%). Prevalence of $S$. aureus ranged from $1.0-4.8 \%$ by product category and $1.2-6.6 \%$ by public supply locations with no significant differences. Significantly higher (10.7\%, 95\% CI: 5.7-19.1; OR=12, 95\% OR CI: 6.1-23.7) in product packed in carton box than in those packed with glass bottle (2.3\%) and metal can (2.4\%) were observed. Considering countries of product origin, $S$. aureus was significantly higher in those from Bangladesh
(17.9\%, 95\% CI: 5.7-19.1; OR=21.6, 95\% OR CI: 10.3-45.6) and Portugal (8.9\%, 95\% CI: 3.5-20.7; OR=9.8, 95\% OR CI: 3.6-26.2) than from Ethiopia (1.3\%, 95\% CI: $0.5-3.2$; OR=1.3, 95\% OR CI: $0.5-3.3)$. With regards to MRSA within studied variable, $0-6.7 \%$ were observed (Table 2).

\section{Antimicrobial resistance pattern}

As shown in Table 3, high (64.3\%) of S. aureus were resistant to erythromycin followed by $32.2 \%$ to ampicillin. Equal proportions (21.4\%) of S. aureus isolates were resistant to streptomycin, amoxicillin and chloramphenicol. Resistant isolates were not observed against gentamycin and trimethoprim-sulfamethoxazole.

Five isolates $(17.9 \%)$ of the total were resistant to cefoxitine and identified as MRSA. All of MRSA were also resistant erythromycin. Equally $4(80.0 \%)$ MRSA were resistant to amoxicillin and chloramphenicol. In contrast, no resistant MRSA were observed to gentamycin, trimethoprimsulfamethoxazole and ciprofloxacin (Table 3).

\begin{tabular}{|c|c|c|c|c|c|c|c|}
\hline \multirow{2}{*}{\multicolumn{2}{|c|}{ Studied risk factors }} & \multirow{3}{*}{$\begin{array}{c}\text { No. of samples } \\
195 \\
\end{array}$} & \multicolumn{4}{|c|}{ Staphylococcus aureus positive } & \multirow{3}{*}{$\begin{array}{c}\text { MRSA positive } \\
\text { No. } \% \\
1(0.5) \\
\end{array}$} \\
\hline & & & \multirow{2}{*}{$\begin{array}{c}\text { No. (\%) positive } \\
8(4.1)\end{array}$} & \multirow{2}{*}{\begin{tabular}{|c|}
$95 \% \mathrm{Cl}$ percentage \\
$2.1-7.9$ \\
\end{tabular}} & \multirow{2}{*}{$\begin{array}{l}\text { OR } \\
4.1\end{array}$} & \multirow{2}{*}{$\begin{array}{c}95 \% \text { OR CI } \\
2.1-8.6\end{array}$} & \\
\hline \multirow{3}{*}{ Product category } & Energy drink & & & & & & \\
\hline & Juice drink & 373 & $18(4.8)$ & $3.1-7.5$ & 5.1 & $3.2-8.1$ & $4(1.2)$ \\
\hline & Bottled water & 206 & $2(1.0)$ & $0.0-3.5$ & 1 & $0.3-3.6$ & $0(0)$ \\
\hline \multirow{4}{*}{ Packaging material } & Carton box & 84 & $9(10.7)$ & $5.7-19.1$ & 12 & $6.1-23.7$ & $2(2.4)$ \\
\hline & Glass bottle & 259 & $6(2.3)$ & $1.1-4.9$ & 2.4 & $1.1-5.2$ & $2(0.8)$ \\
\hline & Metal can & 246 & $6(2.4)$ & $1.1-5.2$ & 2.5 & $1.1-5.5$ & $0(0)$ \\
\hline & Plastic bottle & 185 & $7(3.8)$ & $1.8-7.6$ & 3.9 & $1.9-8.2$ & $1(0.5)$ \\
\hline \multirow{5}{*}{$\begin{array}{l}\text { Public } \\
\text { locations }\end{array}$} & Hotel & 130 & $2(1.5)$ & $0.2-5.4$ & 1.3 & $0.4-5.8$ & $0(0)$ \\
\hline & Open Market & 152 & $10(6.6)$ & $3.6-11.7$ & 7.0 & $3.8-13.2$ & $2(1.3)$ \\
\hline & Restaurants & 166 & $5(3.0)$ & $1.3-6.9$ & 3.1 & $1.3-7.4$ & $1(0.6)$ \\
\hline & Street & 156 & $9(5.8)$ & $3.1-10.6$ & 6.1 & $3.1-11.9$ & $1(0.6)$ \\
\hline & Supermarkets & 170 & $2(1.2)$ & $0.3-4.2$ & 1.2 & $0.3-4.4$ & $1(0.6)$ \\
\hline \multirow{2}{*}{ Source town } & Dire Dawa & 385 & $17(4.4)$ & $2.3-6.9$ & 4.6 & $2.8-7.5$ & $3(0.8)$ \\
\hline & Chiro town & 389 & $11(2.8)$ & $1.6-5.0$ & 3.0 & $1.6-5.3$ & $2(0.5)$ \\
\hline \multirow{8}{*}{ Country of origin } & Bangladesh & 45 & $8(17.8)$ & $9.3-31.3$ & 21.6 & $10.3-45.6$ & $3(6.7)$ \\
\hline & Egypt & 60 & $2(3.3)$ & $0.9-11.4$ & 3.5 & $0.9-12.8$ & $0(0)$ \\
\hline & Ethiopia & 317 & $4(1.3)$ & $0.5-3.2$ & 1.3 & $0.5-3.3$ & $1(0.3)$ \\
\hline & Portugal & 45 & $4(8.9)$ & $3.5-20.7$ & 9.8 & $3.6-26.2$ & $0(0)$ \\
\hline & Saud Arabia & 49 & $4(8.2)$ & $3.2-19.2$ & 8.9 & $3.3-23.8$ & $1(2.0)$ \\
\hline & Thailand & 120 & $3(2.5)$ & $0.9-7.1$ & 2.6 & $0.9-7.6$ & $0(0)$ \\
\hline & UAE Dubai* & 69 & $2(2.9)$ & $0.8-9.9$ & 3.0 & $0.8-11.1$ & $0(0)$ \\
\hline & Yemen & 69 & $1(1.5)$ & $0.3-7.8$ & 1.5 & $0.6-8.4$ & $0(0)$ \\
\hline \multicolumn{2}{|l|}{ Total } & 774 & $28(3.6)$ & $2.5-5.2$ & 3.7 & $2.6-5.5$ & $5(0.6)$ \\
\hline
\end{tabular}

Note: *UAE: United Arab Emirate

Table 2: Prevalence of Staphylococcus aureus and MRSA in commercial soft drink purchased from the two towns by studied risk factors.

\begin{tabular}{|c|c|c|c|c|c|}
\hline \multicolumn{2}{|c|}{ Antimicrobial agents } & \multicolumn{3}{|c|}{ Staphylococcus aureus $(n=28)^{*}$} & \multirow{2}{*}{ MRSA (n=) R. No. \%** } \\
\hline Name of drug & Abbreviation & S. No. (\%) & I. No. (\%) & R. No. (\%) & \\
\hline Erythromycin & ET & $8(28.6)$ & $2(7.1)$ & $18(64.3)$ & $5(100)$ \\
\hline Ampicillin & AMP & $17(60.7)$ & $2(7.1)$ & $9(32.2)$ & $2(40.0)$ \\
\hline Streptomycin & $S$ & $20(71.4)$ & $2(7.1)$ & $6(21.4)$ & $2(40.0)$ \\
\hline Amoxicillin & AML & $18(64.3)$ & $4(14.2)$ & $6(21.4)$ & $4(80.0)$ \\
\hline Chloramphenicol & $\mathrm{C}$ & $21(75.0)$ & $1(4.6)$ & $6(21.4)$ & $4(80.0)$ \\
\hline Cefoxitine & FOX & $23(82.1)$ & 0 & $5(17.9)$ & $5(100)^{\pi}$ \\
\hline Gentamycin & $\mathrm{CN}$ & $24(85.7)$ & 0 & $4(14.3)$ & 0 \\
\hline SXT $T^{\star \star *}$ & SXT & $28(100)$ & 0 & 0 & 0 \\
\hline Ciprofloxacin & CIP & $28(100)$ & 0 & 0 & 0 \\
\hline
\end{tabular}

Note: *S: Susceptible; I: Intermediate R: Resistant; **No intermediate were observed; ***Trimethoprim-sulfamethoxazole; ${ }^{\pi}$ re-tested for cefoxitine Table 3: Antimicrobial susceptibility pattern of Staphylococcus aureus and the MRSA isolated from commercial soft drink products. 
Citation: Hiko A (2018) Staphylococcus aureus and Methicillin Resistant S. aureus in Commercial Soft Drink with Antimicrobial Resistance Test on Isolates in Ethiopia. J Microb Biochem Technol 10: 40-45. doi: 10.4172/1948-5948.1000393

Out of the 28 tested S. aureus, 18 (46.3\%) were resistant against one or more of the drug used in this study. As shown in Figure 1, seven of 28 tested S. aureus isolates were two drug resistant. Out of the 5 MRSA isolates, two each isolates were resistant to three and five drugs.

Out of 18 resistant $S$. aureus isolates, 2 (11.1\%) were resistant erythromycin only as to single drug resistant. As high as six drugs, erythromycin, streptomycin, ampicillin, amoxicillin, chloramphenicol and cefoxitine resistant isolates were 2 (11.1\%). With regards to resistant MRSA, two each isolates were resistant to combination three (amoxicillin, chloramphenicol and erythromycin) and five (erythromycin, streptomycin, ampicillin, amoxicillin, chloramphenicol) drugs (Table 4).

\section{Discussion}

Food contamination with spoilage and/or public health risk pathogenic microbial could occur at any production and processing stage. The contaminate are responsible for quality deterioration, foodborne infections and intoxication, resulting in economic lose and health $[5,26]$. Although all of studied products are within manufacturer shelf life, the present $3.6 \% \mathrm{~S}$. aureus positive commercial soft drink sample indicated the risk associated consumer infection in Ethiopia. The present finding was lower than the $34.15 \%$ S. aureus count positive samples soft drinks [27]. Staphylococcal count of 0 to $2.3 \times 10^{3} \mathrm{CFU} / \mathrm{ml}$ in juices from Dhaka City was also reported [28]. On the other hand, Aljaloud et al. [29] reported absence Staphylococcus in energy drink from Raid-Saud Arabia. Cutter also suggested the use of combination of rigid packaging materials made from metal, glass or plastic provides the heat as most effective inactivating microorganisms during product processing [30]. But, the presence of $S$. aureus at higher proportion $(10.7 \%)$ in carton box packed products than in those packed with glass bottle $(2.3 \%)$ and metal can $(2.4 \%)$ could be either due to the number of sample (48.2\% of studies samples are juice drink) or the presence of high nutrients level for microbial growth. Presence of high nutrients level for microbial growth and the less microbial hurdles properties of many modern soft drinks were suggested factors for microbial survival and multiplication in the products $[1,26]$.

Although high number of sampled product from Ethiopia (40.0\%) and Thailand (15.5\%), present finding indicated those imported from Bangladesh (17.8\%), Portugal (8.9\%) and Saud-Arabia (8.2\%) are highly contaminate with $S$. aureus than those manufactured in Ethiopia (1.3\%). The present finding indicated the presence of $S$. aureus in products from Saud-Arabia (8.2\%) as the counter zero reports of Aljaloud et al in energy drink [29]. This could be either due to differences in the types of studied product, and multiplication of the few microbial present in product during packaging, while distance transportation of the products to Ethiopia [30]. Akond et al. [31] also indicated the posing

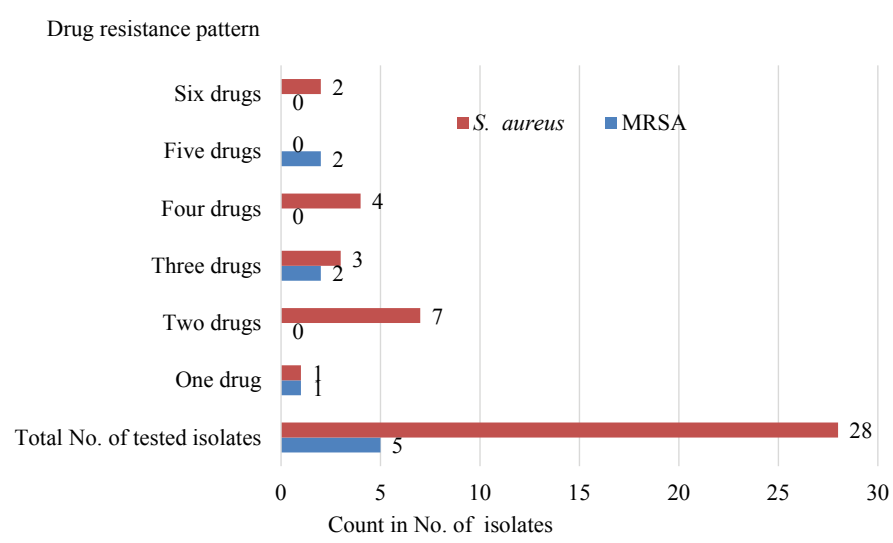

Figure 1: Number of single drug to multiple drugs resistant Staphylococcus aureus and the MRSA isolated from commercial soft drink products.

\begin{tabular}{|c|c|c|c|}
\hline Isolates & Resistance & d the type of drug/s combination & No. (\%) \\
\hline \multirow{12}{*}{ 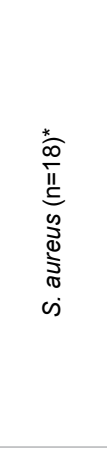 } & Single drug & Erythromycin & $2(11.1)$ \\
\hline & \multirow{4}{*}{ Two drugs } & Ampicillin, erythromycin & $2(11.1)$ \\
\hline & & Chloramphenicol, erythromycin & $1(5.5)$ \\
\hline & & Gentamycin, erythromycin & $3(16.7)$ \\
\hline & & Erythromycin, cefoxitine cefoxitine & $1(5.5)$ \\
\hline & \multirow{2}{*}{ Three drugs } & Ampicillin, amoxicillin, erythromycin & $1(5.5)$ \\
\hline & & Ampicillin, erythromycin, streptomycin & $2(11.1)$ \\
\hline & \multirow{3}{*}{ Four drugs } & Ampicillin, chloramphenicol, erythromycin, streptomycin & $1(5.5)$ \\
\hline & & Amoxicillin, chloramphenicol, erythromycin, cefoxitine & $2(11.1)$ \\
\hline & & Ampicillin, gentamycin, erythromycin, streptomycin & $1(5.5)$ \\
\hline & Six drugs & Erythromycin, streptomycin, ampicillin, amoxicillin, chloramphenicol, cefoxitine & $2(11.1)$ \\
\hline & & Total & $18(100)$ \\
\hline \multirow{4}{*}{ 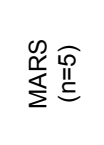 } & Single drug & Erythromycin & $1(20.00)$ \\
\hline & Three drugs & Amoxicillin, chloramphenicol, erythromycin & $2(40.0)$ \\
\hline & Five drugs & Erythromycin, streptomycin, ampicillin, amoxicillin, chloramphenicol & $2(40.0)$ \\
\hline & & Total & $5(100)$ \\
\hline
\end{tabular}

Note: *the $18 \mathrm{~S}$. aureus are including MRSA isolates; **no five drug resistant $S$. aureus, No two drugs and four drugs resistant MRSA isolate

Table 4: Distribution of single drug to multiple drugs resistant Staphylococcus aureus and the MRSA isolated from the studied commercial soft drink products 
Citation: Hiko A (2018) Staphylococcus aureus and Methicillin Resistant S. aureus in Commercial Soft Drink with Antimicrobial Resistance Test on Isolates in Ethiopia. J Microb Biochem Technol 10: 40-45. doi: 10.4172/1948-5948.1000393

substantial public health risks of commercial soft drinks in Bangladesh. The relatively higher and similar $S$. aureus prevalence in products from open market shop (6.6\%), and street $(5.8 \%)$ than in those from hotels, restaurant and supermarkets could be due to differences in handling of the products where the formers sale products under ambient environmental temperature but the latter use refrigeration. Moreira et al. [3] also suggested the contribution of warmer weather and inadequate refrigeration for high levels of contamination as well as diversity and flora of microbial in the commercial product. Moreover, handling the products under uncontrolled temperature could increase multiplication of agent and also responsible for deterioration of the product quality. Juvonen et al. [1] suggested microbiological spoilage of commercial products leads to the deterioration of the sensory quality and changes in the product. Isolation of $5(0.6 \%)$ MRSA strain from commercial soft drinks in present study indicates the consumer risk significances of acquiring infection from such beverage. The risk associated with MRSA infection from food and hospital infection were also suggested [14,15].

Observing a range of (14.3\%- 64.3\%) resistant S. aureus isolates to most of the studied drugs showed the challenge with health risk of public acquiring resistant pathogen. Similar suggestions were given by Livermore [32], Zapun et al. [33], Wayne [34] and Divah et al. [35]. The present $32.2 \%$ S. aureus resistant to ampicillin was lower than the $42.9 \%$ [36]. The present $21.4 \% \mathrm{~S}$. aureus isolates resistant to amoxicillin were lower than $48 \%$ and $62 \%$ reported in isolates from mastitis cow $[37,38]$. The present $21.4 \%$ S. aureus isolates were resistant to chloramphenicol were differed from the zero report of Dibah et al. [35]. Resistant isolates were not observed against gentamycin and trimethoprimsulfamethoxazole.

Five $(17.9 \%)$ of the total S. aureus isolates were resistant to cefoxitine and identified as MRSA. All of MRSA were also resistant erythromycin, equally $4(80.0 \%)$ were resistant to amoxicillin and chloramphenicol. The present resistant profile of all MRSA to erythromycin was similar with the $84.2 \%$ reported by Dibah et al. [35]. The present $46.3 \%$ Staphylococcus aureus and the 5 MRSA isolates resistant to one or more drugs showed the possible risk of acquiring MDR isolates with these beverage [36-38]. The presence of such MRSA isolates were also reported where $28 \%$ were resistant to trimethoprim-sulfamethoxazole and $35 \%$ were resistant to sulfonamides $[39,40]$. MDR Staphylococci posing a growing problem for human health particularly MRSA, the virulent strains [32-34,41]. However, no resistant MRSA against gentamycin, trimethoprim-sulfamethoxazole and ciprofloxacin were observed in this study. Thus, regardless of other factors, these drugs are of choice.

\section{Conclusion}

Staphylococcal contamination of the food product could originates either during the production process, from raw materials, factory environment, packaging equipment and lack of hygiene. The contaminate could be further multiply in the product while poor handling and transportation condition and becoming responsible for product spoilage and consumer health risk. Thus, quality control attention with good handling shall be made while processing, transportation and supply to consumers. The already methicillin resistant $S$. aureus strain showed resistance to one or more six drugs as MDR in this study. Under the present finding, gentamycin, trimethoprim-sulfamethoxazole and ciprofloxacin were drugs are of choice for treatment of staphylococcal infection.

\section{Acknowledgement}

Thematic research area leadership of Dr. Abebaw Adgo was appreciated.

\section{Funding}

Haramaya University Research Grant (HURG) No. HURG-2014-03-04

\section{References}

1. Juvonen R, Virkajärvi V, Priha O, Laitila A (2011) Microbiological spoilage and safety risks in non-beer beverages produced in a brewery environment, Espoo.

2. Sebastia N, El-Shenawy M, Manes J, Soriano JM (2012) Assessment of microbial quality of commercial and home-made tiger-nut beverages. Lett App Microb 54: 299-305.

3. Moreira SR, Schwan RF, de Carvalho EP, Wheals AE (2001) Isolation and identification of yeasts and filamentous fungi from yoghurts in Brazil. Braz $J$ Microb 32: 117-122.

4. Ashanafi M (2002) Microbiological quality of Ethiopian food and beverage Review. Ethiop J Sci 25: 97-140.

5. Jay MJ, Loessner JM, Golden AD (2005) Modern food microbiology, ( $7^{\text {th }}$ Edn) Food Science Text Series. Springer Science, New York, USA.

6. Lawlor KA, Schuman JD, Simpson PG, Taormina PJ (2010) Microbiologica spoilage of beverages compendium of the microbiological spoilage of foods and beverages, in food microbiology and food safety. Springer New York Dordrecht Heidelberg London, pp: 245-284.

7. Vaughan A, O'Sullivan T, van Sinderen D (2005) Enhancing the microbiologica stability of malt and beer - A review. J Institute Brewing 111: 355-371.

8. Yohannes T, Melak F, Siraj K (2013) Preparation and physicochemical analysis of some Ethiopian traditional alcoholic beverages. Afr J Food Sci 7: 399-403.

9. Bayindirli A, Alpas H, Bozoglu F, Hizal M (2006) Efficiency of high pressure treatment on inactivation of pathogenic microorganisms and enzymes in apple orange, apricot and sour cherry juices. Food Control 17: 52-58.

10. Aneja KR, Dhiman R, Aggarwa NK, Aneja A (2014) Review article: Emerging preservation techniques for controlling spoilage and pathogenic microorganisms in fruit juices. Intern J Microb 14.

11. Pereira V, Lopes C, Castro A, Silva J, Gibbs P, et al. (2009) Characterization for enterotoxin production, virulence factors and antibiotic susceptibility test of Staphylococci from food handlers working in an industrial kitchen in Belo Horizonte-MG (Brazil). Rev Microb 25: 161-165.

12. Zadoks R, van Leeuwen W, Barkema H, Sampimon O, Verbrugh H (2000) Application of pulsed-field gel electrophoresis and binary typing as tools in veterinary clinical microbiology and molecular epidemiologic analysis of bovine and human Staphylococcus aureus isolates. J Clin Microbiol 38: 1931-1939.

13. Tewodros W, Gedebou M (1984) Nasal carrier rates and antibiotic resistance of Staphylococcus aureus isolates from hospital and non-hospital populations, Addis Ababa. Trans R Soc Trop Med Hyg 78: 314-318.

14. Kluytmans A (2010) Methicillin-resistant Staphylococcus aureus in food products: Cause for concern or case for complacency? Clin Microbiol Infect 16: $11-15$

15. Gordon J, Lowy D (2008) Pathogenesis of methicillin resistant Staphylococcus aureus infection. Clin Infect Dis 46: 350-359.

16. Karami S, Rahbar M, Yousefi JV (2011) Evaluation of five phenotypic methods for detection of methicillin resistant Staphylococcus aureus (MRSA). Iran J Pathol 6: 27-31.

17. CSA (2014) Federal Democratic Republic of Ethiopia; Central Statistical Agency, Addis Ababa, Ethiopia.

18. DDAEPA (2011) Dire Dawa Administration Program of Adaptation (DDAEPA) to climate change, 2011-Dire Dawa, Ethiopia.

19. Thrusfield M (2005) Sampling in veterinary Epidemiology. (2nd Edn). Black well Science. London, University of Pennsylvania.

20. Montville TJ, Matthews KR, Kniel KE (2012) Food microbiology: An introduction ( $3^{\text {rd }}$ Edn). ASM Press, Washington, DC.

21. Quinn PJ, Markey BK, Carter ME, Donnelly W, Leonard FC, et al. (2002) Veterinary Microbiology and Microbial Disease. Blackwell Science Ltd. London, pp: 191-208.

22. ISO/TS 6888-2 (2005) Microbiology of food and animal feeding stuffs Horizonta method for the detection and enumeration of Staphylococcus spp. Part 1 Detection method. International Organization for Standardization (ISO), ISO 
Citation: Hiko A (2018) Staphylococcus aureus and Methicillin Resistant S. aureus in Commercial Soft Drink with Antimicrobial Resistance Test on Isolates in Ethiopia. J Microb Biochem Technol 10: 40-45. doi: 10.4172/1948-5948.1000393

Central Secretariat, 1 rue de Varembé, Case Postale 56, $\mathrm{CH}-1211$, Geneva 20, Switzerland.

23. Bauer AW, Kirby WMM, Sherris JC, Turck M (1966) Antibiotic susceptibility testing by standard single disc method. Am J Clin Pathol 45: 493-496.

24. CLSI (2012) Performance standards for antimicrobial susceptibility testing Thirteenth informational supplement. Approved standard M100-S13. Clinical and Laboratory Standards Institute (CLSI), Wayne, PA.

25. Brown DFJ, Edwards DI, Hawkey PM, Morrison D, Ridgway GL, et al. (2005) Guidelines for the laboratory diagnosis and susceptibility testing of methicillinresistant Staphylococcus aureus (MRSA): Review. J Antimicrob Chemother 55: 1000-1018.

26. ICMSF (1986) Microorganisms in foods 2. Sampling for microbiological analysis: Principles and specific applications, $\left(2^{\text {nd }}\right.$ edn) ICMSF, Blackwell Scientific Publications: 203.

27. Maduka HCC, Onuorah OR, Okpogba AN, Ugwu CE, Ogueche PN, et al. (2014) Assessment of Some commercial fruit juices commonly consumed in federal university of technology-owerri (FUTO) By microbiological indices. Inter Org Sci Res J Pharm Biolo Sci 9: 56-58.

28. Rahman T, Hasan S, Noor R (2011) An Assessment of Microbiological quality of some commercially packed and fresh fruit juice available in Dhaka city: A comparative study. Stamford J Microb 1: 13-18.

29. Aljaloud SO (2016) Microbiological quality and safety of energy drink available in the local markets in Saudi Arabia. Int J Food Sci Nutr Diet 5: 287-289.

30. Cutter CN (2002) Microbial control by packaging: A review. Crit Rev Food Sci Nutr 42: 151-161.

31. Akond MA, Alam S, Hasan SMR, Mubassara S, Uddin S, et al. (2009) Bacterial contaminants in carbonated soft drinks sold in Bangladesh markets. Intern J Food Microb 130: 156-158.
32. Livermore DM (2000) Antibiotic resistance in Staphylococci. Int J Antimicrob Agents 16: S3-S10.

33. Zapun A, Contreras-Martel C, Vernet T (2008) Penicillin-binding 2. Proteins and beta-lactam resistance. FEMS Microbiol Rev 32: 361-385.

34. Wayne PA (2012) USA: Clinical and Laboratory Standards Institute (CLSI). M100-S21: Performance standards for antimicrobial susceptibility testing. $21^{\text {st }}$ Informational Supplement.

35. Dibah S, Arzanlou M, Jannati E, Shapouri R (2014) Prevalence and antimicrobial resistance pattern of methicillin resistant Staphylococcus aureus (MRSA) strains isolated from clinical specimens in Ardabil, Iran. Iran J Microbiol 6: 3 163-168.

36. Pesavento G, Ducci B, Gomodo N, LoNostro A (2007) Antimicrobial resistance profile of Staphylococcus aureus isolated from raw meat: A research for methicillin resistant Staphylococcus aureus (MRSA). Food Control 18: 196-200.

37. Girma S, Mammo A, Bogele K (2012) Study on prevalence of bovine mastitis and its major causative agents in West Harerghe zone, Doba district, Ethiopia $\mathrm{J}$ Vet Med Anim Health 4: 116-123.

38. Belayneh R, Belihu K, Wubet A (2013) Dairy cow's mastitis survey in Adama Town, Ethiopia. J Vet Med Anim Health 5: 281-287.

39. Daka D, Solomon G, Dawit Y (2012) Antibiotic-resistance Staphylococcus aureus isolated from cow's milk in the Hawassa area, South Ethiopia. Ann Clin Microbiol Antimicrob 11: 26.

40. Kohl RL, Burdeska IA. (1992) Frequency and transferability of trimethoprim and sulfonamide resistance in methicillin-resistant Staphylococcus aureus and Staphylococcus epidermidis. J Chemother 4: 67-71.

41. Kaur DC, Chate SS (2015) Study of antibiotic resistance pattern in methicillin resistant Staphylococcus aureus with special reference to newer antibiotic. $J$ Global Infect Dis 7: 78-84. 